\title{
Conception of Quebec Students in Teacher Education Regarding the Construction Modes of Science Knowledge
}

\author{
Abdeljalil Métioui ${ }^{1, *}$, Louis Trudel $^{2}$ \\ ${ }^{1}$ Département de didactique, Université du Québec à Montréal, Montréal, Canada \\ ${ }^{2}$ Faculté d'éducation, Université d'Ottawa, Ottawa, Canada \\ *Corresponding author: metioui.abdeljalil@uqam.ca
}

Received July 11, 2013; Revised July 24, 2013; Accepted September 23, 2013

\begin{abstract}
In the present research, we identified the conceptions of 184 students registered in teacher education for the primary order, in relation to construction modes of scientific notions. To characterize their conceptions, we constructed a questionnaire with numerous choices (QCM) regrouping 16 questions. For every question, the student had to encircle the number which corresponds to its choice (1: In disagreement; 2: I do not know or 3: In agreement) besides pointing out the reasons of his choice. Questions were formulated around 4 topics: (1) the objectives of science and its development limits, (2) the role of measure, experimentation and theory in science, (3) the evolution of science: continuity and breakthrough, and (4) logico-mathematical reasoning in sciences. For example, regarding measure, experimentation and theory, their conceptions oscillate between several opposed tendencies, as realism and empiricism. Also, according to the majority, the development of science is uninterrupted and corresponds to an improvement of theories and of laws developed across different epochs and that theory must follow experience.
\end{abstract}

Keywords: science, knowledge, conception, teacher education, primary school

Cite This Article: Abdeljalil Métioui, and Louis Trudel, "Regarding the Construction Modes of Science Knowledge.” American Journal of Educational Research 1, no. 8 (2013): 319-326. doi: 10.12691/education-1-8-9.

\section{Introduction}

It is a well known fact that from the primary school, secondary and to the university, the formal teaching of the disciplines as the physics, the chemistry and mathematics do not bring the expected results [1]. Several studies demonstrate that the pupils cannot formulate the scientific generalizations necessary to solve non canonical problems. In this regard, Niedderer [2] notes that after learning physics at the university level, students still demonstrate a lack of qualitative understanding of the basic concepts. How can one explain these results? The research shows us that the conceptions of student before teaching, generally "naïve", stay in spite of a formal teaching. The young people elaborate very early explanatory models of natural phenomena and those models are shown to resist to traditional teaching. The merit comes back, among others, to Posner et al. [3] and Matthews [4] to have explained the phenomenon of the resistance to change of these naïve conceptions while establishing a certain parallelism between the pupils' conceptions of the natural phenomena and the various theories held by scientists throughout the history of the sciences.

In this view, one will understand why it is prescribed in the majority of the training programs for preservice teachers to include some history of science in science teaching. For example, in the science program of the ministry of the education of Quebec [5] one puts the emphasis on the development of expertise in science and technology among the pupils. According to the instructions of the ministry, one must teach these matters while taking into account philosophical and cultural aspects, among others, that have marked the most their developments during history. To this end, it would be necessary that teachers know how these factors intervene in science and technology learning and how scientists proceed to develop their knowledge. While reviewing literature, one must take note of the absence of systematic studies clarifying the conceptions of primary school teachers about experimentation, theory and scientific method. Otherwise, in the case of the secondary school teachers, we note some research in this area $[6,7,8,9,10]$. The present study follows the same line of research with respect to teachers' conceptions about the experimental process and the development of science throughout history. To this end, we are going to specify our conceptual framework, followed by a description of the sample and the retained methodology as well as a description of our results followed by a discussion about the impact of the present study upon teachers' training.

\section{Conceptual Framework}

The present research is focused around 4 themes: (1) the objectives of the science and its limits of development; 
(2) the status of the measurement, the experimentation and the theory in sciences; (3) the evolution of science: continuity and breaks through; (4) the logicomathematical reasoning in sciences.

Below, we list related researches in history and in epistemology of the sciences, our conception on each of these themes and the results of the experimentation.

This conceptual analysis will constitute, on a methodological level, our reference grid to analyze the discourse of pre-service students in science teaching at the primary order.

\section{The Objectives of the Science and Its Limits of Development}

\subsection{Science has for Objective the Search for "Reality"}

This realist representation of science implies the existence of a knowable and absolute reality, independent of our observations or our instruments of measure [11,12]. However we know, since the advent of relativistic quantum mechanics, that the research of "reality", as independent and neutral entity, has been put into question since it is unthinkable, or even impossible, to study a natural or constructed phenomenon without disrupting it. In this view, one must consider science for example as the result of a cognitive activity allowing the scientists to construct representations of the universe that constantly evolve and that the research of the reality belongs more to our personal convictions.

\subsection{Science has for Objective to Describe and Explain Nature}

For a long time, science had effectively the ambition to describe and explain nature. Today we know, since the works of the famous physicist Heisenberg, that the scientist does not have the pretention anymore to reach the knowledge of the Nature in itself; rather he is interested in phenomena of which he is both the spectator and the actor, phenomena his instruments of measurement and methods of investigating transform once and for all [11,12].

\subsection{The Scientists are Motivated by the Research of Truth}

Research of truth is not an objective for science, but rather for philosophy, because the scientific knowledge developed by the researchers result from an interaction between the studied phenomenon and the theoretical framework to which they adhere. Besides, we know that several scientists are motivated by the research of glory and prosperity rather than by the research of "truth". To reach these objectives, some scientists may even resort to immoral practices such as fraud and plagiarism [13].

\section{The Role of Measure, Experimentation and Theory in Science}

\subsection{Scientists First Do Some Measures before Defining the Concepts}

This representation joins a current of thought according to which scientific reality is the very measure, more than the measured object.

In this perspective, the scientists tend to measure first and to define later; the instrument seems to precede theory [14]. This representation was criticized severely since the advent of modern physics where the measure of a physical variable takes place inside a given theoretical framework and outside of it, it remains unexplained.

\subsection{The Experience is to the Basis of All Scientific Knowledge and One Cannot Apply for Anything without Verifying It in the Laboratory}

This conception is erroneous since all experience is theoretical interpretation $[2,11]$. The scientific theories are concrete since to develop them, one must resort to our sensory device. This representation granting a central place to the sense organs in the development of scientific theories belongs to naïve inductivism $[12,15]$. This conception is erroneous because in the history of science, the recourse to senses was often considered a source of mistake and imprecision (the electric fluid, the heat as substance, etc.). Then, the science starts with a question and not with an observation, as stated in the model of the experimental method inherited of Claude Bernard.

\section{The Evolution of the Science (Continuity and Rupture)}

\subsection{The Scientific Problems of the Past are Bound Intimately With Those of Today}

The scientific work takes place while being based on a set of central concepts that provides, for a group of researchers, problems and types of solution [16]. For example, the problems associated with free fall of objects, defined in the framework of the physics of Aristotle's movement, are defined differently in the framework of Galilee. Hence, in the last one compare the first, the framework excluded from its explanations the prejudices of mythical order to the benefit of a rational explanation to give, for example, account of the free fall. In this perspective, the scientific problems of the past are not bound intimately with those of today.

\subsection{Tomorrow's Scientific Theories Will be in the Extension of Today's Theories}

As previously stated, we think that tomorrow's scientific theories will not be extensions of today's theories. Let's note with respect to this topic that the present works in physics are throwing into question the space-time theory formulated by Einstein [17]. According to Bachelard, the scientific theories developed through different times are in discontinuity and in epistemological rupture. The passage of a theory to another constitutes a radical change in the epistemological premises that compose the theoretical building. An interesting illustration of this rupture notion is given by the historic evolution of the mass concept explained by Bachelard [18]. In the same way, Kuhn [16] qualifies the passage of a theory to 
another of scientific revolution that occurs when the scientists are incapable of solving a certain number of problems in the framework of a given theory, the central concepts that underlie this theory must be modified radically; for example, the notions of movement and applied force in the Galilean physics have been redefined in the setting of the Newtonian physics to solve some enigmas such as the problem of the simultaneity. Otherwise, Kuhn did not qualify a revolution when this development takes place inside a given paradigmatic setting and in this view one can speak of a continuation of improvement and sophistication of the theories.

\subsection{When a New Theory Can Predict More Experimental Results Compared to Another Theory, It Replaces It}

Such as change is not so simple because it can meet big reticence's on behalf of the scientific community, or even a dismissal of the theory in spite of its superiority. We have several examples of scientists that could not adhere to a new theory for reasons that have nothing to do with its formal framework.

\section{The Logico-mathematical Reasoning in Sciences}

\subsection{The Scientific Theories Lean on Logico- Mathematical Reasoning}

Mathematics is indispensable to the development of physics, but is a field of knowledge completely different from the physics since they are independent of the observations of the real world (Le Strat, 1990). In this perspective, the scientists do not conceive their theories while resorting solely to logico-mathematical reasoning $[19,20]$.

\subsection{In the Development of His Thought, the Scientist Excludes All Recourse to His Religious Convictions}

This representation is false. Indeed, at the time of the development of the quantum mechanics, some physicists had the difficulty to reconcile the probabilistic interpretation of the physical phenomena on an atomic scale with their metaphysical conceptions. To this topic, let's recall the famous controversy between Einstein and Bohr [21] capable to sum up in a simple picture according to which, for the first "God doesn't play the dice" and for the second, "God plays the dice."

\section{Methodology}

\subsection{Subjects}

Research has been achieved in the context of a course aiming to train students to teach science at the primary order. The sample was constituted of 184 of these students, the majority of whom were of feminine gender, registered in second year of the program in preschool and primary teaching offered by a faculty of education.
The average age was 23 years; the majority came from the sector of the humanity so that their previous science knowledge was limited to high school science. Specifically, they had usually followed courses of ecology, physical sciences and human biology during their secondary studies. To collect their representations, with a multiple choice questionnaire (QMC) of a length of 90 minutes has been elaborated, such duration being sufficient for our respondents to answer all questions.

\subsection{Instrument}

Table 1. Questionnaire to multiple choices

To answer the following questions, you have to encircle the number that corresponds to your choice, followed of a brief commentary.

1. The science has for object to discover the reality. Explain your.choice.

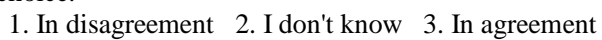

2. To study the properties of the phenomena, the scientists first do some measures; and then define the concepts. Explain your choice.



3. The direction followed by the science of today is determined by orientations taken by previous generations of scientists. Explain your choice.

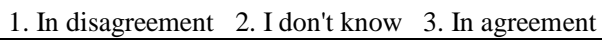

4. The scientists present their theories under the format of logicomathematical reasoning. Explain your choice.

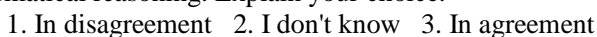

5. In the development of his thought, the scientist excludes all recourse to his religious convictions. Explain your choice.

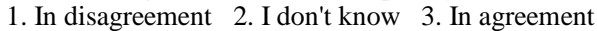

6. The objective of the science is to study the natural phenomena. Explain your choice.

1. In disagreement 2 . I don't know 3 . In agreement

7. The scientific problems of the past are bound intimately to those of today. Explain your choice.

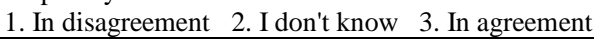

8. The scientists are motivated by the research of the truth. Explain your choice.

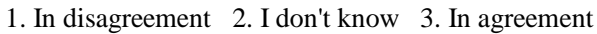

9. The scientific progress results in an improvement of the scientific theories. Explain your choice.



10. To develop a scientific theory, one must do some experiences first. Explain your choice.

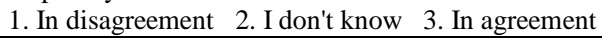

11. The new scientific concepts result from the application of a logical thought. Explain your choice.

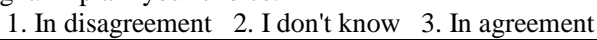

12. Tomorrow's scientific theories will be the extension of the theories of today. Explain your choice.

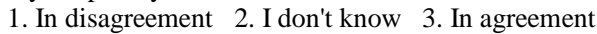

13. So that a theory replaces another one, it must predict more experimental results. Explain your choice.

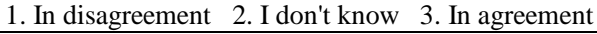

14. The scientists often resort to their senses (to touch, smell, hearing, etc.) in order to help them develop their theories. Explain your choice.

1. In disagreement 2 . I don't know 3 . In agreement

15. A scientist must always argue in a coherent and just manner. Explain your choice.

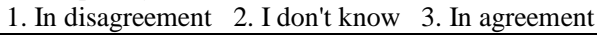

16. The science has for object the study of nature. Explain your choice.

1. In disagreement 2. I don't know 3. In agreement

To characterize students' conceptions, we constructed a multiple choice questionnaire (QMC) regrouping 16 illustrated statements reproduced in Table 1 and clarified before in our conceptual framework. To answer each question, the student had to circle the number that corresponds to his/her choice (1: In disagreement; 2: I don't know or 3: In agreement) and to explain the reasons of his/her choice. The stage of explanation is important since it allows the researcher to be sure that the choice of 
the student is not unpredictable and is founded on clarified reasoning.

For the benefit of clarity, we presented these questions according to the following themes as illustrated in Table 2, although the statements were not classified in themes in the questionnaire answered by the students.

Table 2. Regrouping of the questions according to the themes Theme 1: The objectives of the science

(1). The science has for object to discover the reality.

(6). The objective of the science is to study the natural phenomena.

(8). The scientists are motivated by the research of the truth.

(16). The science has for object the study of nature.

Theme 2: The statute of the measure, the experimentation and the theory in sciences

(2). To study the properties of the phenomena, the scientists first do some measures; and then define the concepts.

(10). To develop a scientific theory, one must do some experiences first.

(13). So that a theory replaces another one, it must predict more experimental results.

(14) The scientists often resort to their senses (to touch, smell, hearing, etc.) in order to help them develop their theories.

Theme 3: The evolution of the science (continuity and rupture)

(3). The direction followed by the science of today is determined by orientations taken by previous generations of scientists.

(7). The scientific problems of the past are bound intimately to those of today.

(9). The scientific progress results in an improvement of the scientific theories.

(12). Tomorrow's scientific theories will be the extension of the theories of today.

Theme 4: The logico-mathematical reasoning in sciences

(4). The scientists present their theories under the format of logicomathematical reasoning.

(5). In the development of his thought, the scientist excludes all recourse to his religious convictions.

(11). The new scientific concepts result from the application of a logical thought.

(15). A scientist must always argue in a coherent and just manner.

\section{Results}

The Table 3,Table 4,Table 5 and Table 6 presents the percentages of the answers given by students as well as some justification offered by respondents of their choice.

\subsection{Percentages of Students' Agreement to Questions of Theme 1: The Objectives of Science}

With respect to theme 1 on the objectives of the science (see Table 2), the percentages of answers of the students to the questions of this theme as well as some justifications they brought are described in Table 3. Thus, for question 1 (see Table 3), a very important fraction of the students considers that the object of science is to discover reality (85\%). With respect to the study of natural phenomena (question 6, Table 3), even though a majority considers that it is an objective of the science (62\%), an important fraction is in disagreement with the statement (34\%), because it doesn't include, for example, the phenomena created by the man in the laboratories. Otherwise, for question 8 (Table 3), even though an important part of the students $(68 \%)$ is of opinion that the scientists are motivated by the research of truth, a minority among them is in disagreement with the statement (21\%), while affirming for example that the scientists rather try to understand how and why the studied phenomena occur.
Finally, for question 16 (Table 3), a majority of students (67\%) considers that the object of science is to study the nature, whereas a minority is in disagreement (21\%), because they consider, for example, that the science also pursues the objective to study the phenomena constructed by the man or the technology.

Table 3. Percentages of the answers followed of some relative subjects to the theme 1 (Objectives of the science: reality, truth and nature)

\begin{tabular}{|c|c|c|}
\hline \multicolumn{3}{|c|}{ 1. The science has for object to discover the reality. } \\
\hline In disagreement & I don't know & In agreement \\
$17 / 184: 9 \%$ & $11 / 184: 6 \%$ & $156 / 184: 85 \%$ \\
\hline
\end{tabular}

In disagreement: " I would say more to explain it than to discover it. The reality is in front of us and we observe it, while the science explains us what one observes. » (E 6)

I don't know: " I believe that it has indeed for goal to discover the reality, but that it must also explain it. » (E 44)

In agreement: « The science has for object to observe and to construct a reasoning permitting to formulate theories and notions that explain real phenomena extracted from our environment from here and now.

The scientists look for, in other words, to understand and to solve problems of the reality. » (E 26)

6 . The objective of the science is to study the natural phenomena.

\begin{tabular}{c|c|c}
\hline In disagreement & I don't know & In agreement \\
$62 / 184: 34 \%$ & $7 / 184: 4 \%$ & $115 / 184: 62 \%$
\end{tabular}

In disagreement: « There are not only the natural phenomena: it is possible to create a situation of a voluntary act and to have to explain the concept associated with it. For example, the study of electrostatics can be made with the meteorological natural phenomena but also with a rubbed ball to produce the phenomenon at different degrees. » (E1) I don't know: " The science permits to study the natural phenomena, but also the phenomena of human nature. Even though it is different, these are all natural phenomena. » (E 80)

In agreement: « The objective of the science is to describe the nature while interpreting, with the experimental approach, the observations that are being made. More precisely, the science tries to explain the problems found in nature, to submit phenomena to laws and to propose new concepts bound to the study of nature. » (E 26)

8. The scientists are motivated by the research of the truth.

\begin{tabular}{c|c|c}
\hline In disagreement & I don't know & In agreement \\
38/184: $21 \%$ & $21 / 184: 11 \%$ & $125 / 184: 68 \%$ \\
\hline
\end{tabular}

In disagreement: " The scientist tries to discover the explanations, the laws and the principles of the phenomena that surround us. In this sense, he doesn't want to discover the truth but to understand why and how these phenomena occur. " (E32)

I don't know: «I don't know if the scientists are motivated mainly by the research of the truth, I believe that they are motivated more to find some solutions to the problems of illness, famine... » (E18)

In agreement: « I believe that there is not anything better than the science to prove a truth, because a scientific theory is always based on concrete and serious (experimentation, research, analysis, etc.) scientific proofs... » (E33)

16. The science has for object the study of nature.

\begin{tabular}{c|c|c}
\hline In disagreement & I don't know & In agreement \\
40/184: $22 \%$ & $20 / 184: 11 \%$ & $124 / 184: 67 \%$ \\
\hline
\end{tabular}

In disagreement: « The science doesn't study the nature exclusively, or of the natural phenomena. I believe that the science also studies phenomena provoked by the man or technologies developed exactly by the science. » (E22)

I don't know: " Maybe, but I am not sure that it is the only object that seems to me to regroup domains however a lot. » (E33)

In agreement: « The science tries to explain the natural phenomena that govern the universe. To understand how operates the environment and the variables that there constantly intervenes. The science permits to observe the mysterious phenomena and the strengths of the nature as well as to find the working of the nature progressively. » (E26)

\subsection{Percentages of the Answers and Subject of Student: Theme 2}

With respect to theme 2 on the status of measure, experimentation and theory in science (see Table 2), the percentages of answers of the students to the questions of this theme as well as some justifications they brought 
forth are described in Table 4. With regard to the survey of the properties of the phenomena (question 2, Table 4), half of the students (50\%) considers that the scientists first do measures, and then define the concepts. Still in relation to question 2, an important part of the students doesn't know (31\%) whereas a minority is in disagreement with the statement (19\%) and consider, for example, the inverse order where the hypothesis is emitted before the measure.

Table 4. Percentages of the answers followed of some relative subjects to the theme 2 (Measure, experimentation and scientific theories)

2. To study the properties of the phenomena, the scientists first do some measures; and then define the concepts.

\begin{tabular}{c|c|c}
\hline In disagreement & I don't know & In agreement \\
35/184: $19 \%$ & 57/184: $31 \%$ & $92 / 184: 50 \%$ \\
\hline
\end{tabular}

In disagreement: " Before doing some measures, I would take the time to make a hypothesis, to note my observations and to make some research on similar phenomena. Then, I would take some measures and I would define the concepts that return themselves of it. I am in disagreement because I think that the scientists follow the scientific progress that includes several stages. » (E 22)

I don't know: «I would be inclined to say that this affirmation is true. The scientists take some measures and attempt to discover some constants. Once these constants are discovered, then they can define the concepts. " (E16)

In agreement: " The scientists make several experiences before defining some concepts; it is to arrive to true concepts based on measures. » (E 5)

10. To develop a scientific theory, one must do some experiences first.

\begin{tabular}{l|l|l}
\hline In disagreement & I don't know & In agreement
\end{tabular}
34/184: $19 \%$ $11 / 184$

\begin{tabular}{l|l|l} 
34/184: $19 \%$ & $11 / 184: 6 \%$ & $139 / 184: 75 \%$ \\
\hline
\end{tabular}

In disagreement: « A lot of scientists as Galilee made some experiences to prove their already existing theories. » (E6)

I don't know: « I believe that one must start by emitting a hypothesis before conducting the experiences. The experiences bring the proofs that will permit to strengthen the theories. » (E21)

In agreement: " It is while one makes an experiment that he can develop scientific theories. » (E12)

13. So that a theory replaces another one, it must predict more experimental results.

\begin{tabular}{c|c|c|}
\hline In disagreement & I don't know & In agreement \\
63/184: $34 \%$ & 51/184: $28 \%$ & $70 / 184: 38 \%$ \\
\hline
\end{tabular}

In disagreement: "So that a theory replaces another one, it must refute the first merely. It must bring new facts. »(E3)

I don't know: "I believe that once the theories are exposed by the scientists, it is the society that determines those that predominate. It is not necessarily a question of predictions of results. The critiques and the choices of a society can be influenced by number of other factors that are not always directly in tie with the experimentation. » (E9)

In agreement: "Undoubtedly that it must prove with the help of experimental results that it is truer than another. A simple theory on writing that didn't give its proofs with the real cannot be taken in consideration. » (E 38)

14. The scientists often resort to their senses (to touch, smell, hearing, etc.) in order to help them develop their theories.

\begin{tabular}{c|c|c}
\hline In disagreement & I don't know & In agreement \\
36/184: $20 \%$ & $26 / 184: 14 \%$ & $122 / 184: 66 \%$ \\
\hline
\end{tabular}

In disagreement: « They resort to instruments of precise measure. The human body is not precise enough and our perception can be altered by many external influences. » (E6)

I don't know: « The senses permit to observe. However, they can also distort some results. We only have to think for example about the optical illusions. » (E16)

In agreement: " It is obvious that the five senses must be implied in the development of scientific theories.If the scientist cannot observe or cannot manipulate the objects for example, it will be a lot more difficult for him to clarify an adequate theory being based on the veracity of the supporting facts». (E30)

Otherwise, considering question 10 (Table 4), a majority (75\%) considers that one must make the experiences to develop a theory, whereas a minority is opposed (19\%), mentioning for example that Galilee made some experiences to prove an already existing theory. Apart from that, the opinions of the students are shared almost equally with respect to question 13 (Table 4), considering the replacement of a theory by another. If an important fraction thinks that for such a replacement to occur, the first theory must predict more results than the second (38\%), a good number is uncertain (28\%), mentioning, among others, that the experimental results are not the only criteria to decide the choice of a theory, whereas others are opposed (34\%), insisting, for example, on the criteria of falsification of the theory by experience.

With respect to the development of the theories (question 14, Table 4), the majority grants an important role to the senses (66\%), whereas others don't know, (14\%) mentioning, for example, that the use of the senses can distort the results, whereas others are in disagreement (20\%), proclaiming the superiority of the measure instruments for example.

\subsection{Percentages of the Answers and Subject of Student: Theme 3}

With respect to theme 3 concerning the evolution of the science (see Table 2), the percentages of answers of the students to the questions of this theme as well as some justifications that they brought forth are described in Table 5 . To the question 3 on the direction of today's science, the big majority of the students (72\%) is of opinion that it is determined by the previous generations of scientists mentioning for example its cumulative character whereas others, in disagreement (17\%), underline its evolutive character for example. Some are uncertain (11\%) providing arguments that combine the precedents. With respect to the ties between the problems of yesterday and today (question 7, Table 5), the majority thinks that they are linked (61\%), granting relatively to the first the role of framing the second. In contrast, some are in disagreement (19\%), underlining for example that the reality of the scientists change and the problems also. Finally, others don't know (20\%) because for example it is necessary according to them to really know the problems of yesterday and of today in order to be able to compare them. To the question 9 (Table 5) if the scientific progress results in an improvement of the theories, the very big majority is in agreement (81\%). Among those that are in disagreement or don't know, the first ones (16\%) mention other consequences of progress, for example the practices of every day, whereas the second (3\%) rather insist for example on the interdependence between the scientific progress and the development of theories.

With respect to the evolution of theories (question 12, Table 5), the majority thinks that tomorrow's theories will be in the extension of those of today (66\%) whereas several think the opposite (26\%), while granting for example a certain role to the new discoveries.

Table 5. Percentages of the answers followed of some relative subjects to the theme 3 (Evolution of the science: continuity and rupture)

3. The direction followed by the science of today is determined by orientations taken by the previous generations of scientists.

\begin{tabular}{c|c|c}
\hline In disagreement & I don't know & In agreement \\
$31 / 184: 17 \%$ & $20 / 184: 11 \%$ & $133 / 184: 72 \%$
\end{tabular}

In disagreement: « I don't believe that today's science is determined in the past. It is clear that the discoveries of the past have an important influence in the science of today, but the science is in constant evolution and it is why according to me, science is centered more on the stakes of news and even future, as the environment. » (E20) I don't know: « I don't know because I believe that every day the 
scientists make the discoveries that can throw into question orientations taken by the previous generations of scientists, therefore they don't necessarily follow the same direction. However, they are probably influenced one way or the other by what their predecessors made. » (E 13)

In agreement: « It seems true, because now the science evolves. It tries to find new discoveries. Today's science doesn't question again the science of yesterday. It goes toward the before. Then, today's science leans on orientations taken by the previous generations of scientists. » (E 3)

7. The scientific problems of the past are bound intimately to those of today

\begin{tabular}{|l|l|l}
\hline In disagreement & I don't know & In agreement
\end{tabular}
35/184: $19 \%$ $37 / 184:$

disagreement: " During the time the reality of the scientist's

changes. The problems to which the scientists are confronted are different from those that one recovered in the past. » (E67)

I don't know: "It would first be necessary that I know the scientific problems of the past to judge if they are at the source of our contemporary problems. » (E38)

In agreement: " Certainly! Not only the problems, but also their resolution. The scientist's objective is to pull a conclusion: if some problems have been identified in the past, they constitute an element of analysis for the scientists of today. Of the same stroke, the gradual resolution of these problems serves as tracks for other problems, since it is a source of concepts. » (E1)

9. The scientific progress results in an improvement of the scientific theories.

\begin{tabular}{|l|l|l}
\hline In disagreement & I don't know & In agreement
\end{tabular}

\begin{tabular}{l|l|l} 
29/184: $16 \%$ & $5 / 184: 3 \%$ & $150 / 184: 81 \%$ \\
\hline
\end{tabular}

In disagreement: " The scientific progress results in an improvement of the scientific theories, but especially by an improvement with regard to the practice, the concrete life of every day (medicines, means of transportation, technologies, etc.). » (E28)

I don't know: "It is as the chicken and the egg". Difficult to say what comes in first. Progress permits to perfect the conceived theories, but the theories are also to the basis of progress. It is a vicious circle. The two are in constant interdependence. The two work equally. » (E9) In agreement: « The scientists can make scientific discoveries indeed and can refine theories already emitted by other scientists of the past. They make progress therefore the science. » (E12)

12. Tomorrow's scientific theories will be the extension of the theories of today.

\begin{tabular}{l|l|l}
\hline In disagreement & I don't know & In agreement
\end{tabular}

\begin{tabular}{l|c|c} 
47/184: $26 \%$ & $15 / 184: 8 \%$ & $122 / 184: 66 \%$ \\
\hline
\end{tabular}

In disagreement: " These theories won't necessarily be the extension. During the next years, it goes doubts to have itself there of it of new scientific theories coming from new discoveries. Some theories can be the extension, but not all. » (E4)

I don't know: "One cannot be certain of it, but I imagine that an important continuity exists in the world of the science. A scientist's life is not long enough to allow him to arrive to an outcome (by himself). The scientists must hand over the torch. " (E21)

In agreement: « The scientists constantly try to modify or to improve the former theories. It goes without saying that tomorrow's scientists will work on the theories that we know today. It is certain that they will develop some new theories, but the majority of them already exist now. » (E11)

\subsection{Percentages of the Answers and Subject of Student: Theme 4}

With respect to theme 4 concerning the logicomathematical reasoning used in sciences (Table 2), the percentages of answers of the students to the questions of this theme as well as some justifications that they brought are described to Table 6 .

With respect to presentation of theories, the majority (72\%) thinks that the scientists present their theories under logico-mathematical form, in part because they are rational beings, in part to convince others.

Among those that are in disagreement (19\%) or don't know, (9\%) some among those opposed mention that the exposed theories cannot be logical for everybody whereas others mention for example that they don't know what is a logical reasoning or doubt that other forms of scientific reasoning exist.

Table 6. Percentages of the answers followed of some relative subjects to the theme 4 (The logico-mathematical reasoning in sciences)

4. The scientists present their theories under the format of logicomathematical reasoning.

\begin{tabular}{c|c|c}
\hline In disagreement & I don't know & In agreement \\
34/184: $19 \%$ & $17 / 184: 9 \%$ & $133 / 184: 72 \%$
\end{tabular}

In disagreement: " It is false to affirm it since the scientists present their theory according to their hypotheses. However, it is not because his hypothesis is logical in his head that it is logical for all. » (E 31) I don't know: "I presume that yes, the scientists take the facts and anything else as a basis. They experiment all their theories and don't throw any experiment by imagination. All is real and logical. However, I don't know what a logical reasoning is. I don't know if other types of reasoning exist that the scientists could use. » (E 3)

In agreement: " According to me, a scientist defines herself like a logical being. It is a rational being who writes her theories according to truthful and controllable facts. If the scientists wrote their theories under an illogical form, they would not succeed in convincing people of their theories. » (E4)

5. In the development of his thought, the scientist excludes all recourse to his religious convictions.

\begin{tabular}{c|c|c} 
In disagreement & I don't know & In agreement \\
41/184: $22 \%$ & 29/184: $16 \%$ & $114 / 184: 62 \%$
\end{tabular}

In disagreement: " Although the scientist makes everything that is in his possible to be objective, I don't believe that it is possible, because the religion exercises a big influence on the way of thinking of people and that, to a lot of levels. The science and the religion make rarely good household, but of there to say that a scientist can make abstractions of the principles to which he believes, I doubt. Even hidden in a corner of the brain, the religious convictions can influence a man's scientific reasoning. » (E 9)

I don't know: «I think that maybe it depends on the scientist. It is not because someone is scientific that he doesn't have any religious beliefs. I don't know if they always put their convictions of side. » (E 11)

In agreement: " The religion is to the contrary of the science. The science studies the concrete and the real whereas the religion rests on personal beliefs. The scientist's religious convictions cannot demonstrate out of all doubt that his thought is true or false. It requires the observable facts and the concrete proofs. » (E 7)

11. The new scientific concepts result from the application of a logical thought.

\begin{tabular}{c|c|c}
\hline In disagreement & I don't know & In agreement \\
$42 / 184: 23 \%$ & $34 / 184: 18 \%$ & $108 / 184: 59 \%$
\end{tabular}

In disagreement: « A scientist may have discovered a new concept by trial and error, without having used a structured and logical approach. It is true, however, that in most cases, to discover new concepts, the scientists use the logical thought, for example while modifying a variable at a time. » (E11)

I don't know: «I don't know what the explanations constituted the basis of the new scientific concepts. Is this maybe the application of the logical thought? » (E12)

In agreement: "The science uses the logic regularly since it is necessary to show evidence of a logical reasoning to elaborate a concept. The logical thought permits to reject the false reasoning. (E14)

15. A scientist must always argue in a coherent and just manner.

\begin{tabular}{|l|l|r}
\hline In disagreement & I don't know & In agreement
\end{tabular}

\begin{tabular}{c|c|c} 
51/184: $28 \%$ & $11 / 184: 6 \%$ & $122 / 184: 66 \%$
\end{tabular}

In disagreement: « The scientists stay above all human beings. It is therefore impossible that they always argue in a just way, without ever being mistaken. The mistakes are part of the life of everybody. » (E11)

I don't know: « I am not sure of the answer to this question. I believe that the scientist should try to argue in a coherent and just manner, but I don't think that he always does it. I believe that he can sometimes be guided by other goals. » (E22)

In agreement: "So that a theory is believable and is taken in account, it must to be structured and justified. So that it is possible, a scientist has the duty to reason so that the argument he advances is coherent and just. » (E28)

With regard to the place of religion in the evolution of scientific thought (question 5, Table 6), the majority thinks that religion and science exclude themselves 
mutually (62\%), some mentioning that the religion is based on personal convictions whereas the science must demonstrate its affirmations.

Among those that are in disagreement with the statement (22\%) or don't know, (16\%) some of those in disagreement mention that the religion exercises a big influence on the way people thinks, including the scientists, whereas others, who don't know, doubt that it is possible for a scientist to put his religious convictions of side.

With respect to the application of logical thought (question 11, Table 6), the majority thinks that it results in new scientific concepts (59\%), for example that it encourages theory construction as well as discounts the erroneous reasoning's. Among those that are in disagreement (23\%) or don't know, (18\%) the first ones advance for example that there are other ways to elaborate new concepts (by trials and errors).

With regard to the arguing of the scientists (question 15, Table 6), the majority thinks that it should be adequately (66\%) coherent and conducted, because to convince, for example, a theory must be structured and justified.

Those that are in disagreement (28\%) mention for example that the scientists being also humans, it is impossible to them to present a coherent and adequate arguing always, and that the mistakes are part of life.

\section{Analysis of the Data}

The answers advanced by these students bring us to conclude that the majority have representations that appear in defect, compared to those to which we adhere and that are presented in the developed previously conceptual framework.

Thus, according to several participants, the science limits itself to the survey of the natural phenomena (62\%) and of the nature $(67 \%)$ and has for objective the study of the reality (85\%) and the discovery of truth (68\%). To this end, scientists must describe in an objective way their observations while resorting directly to their senses (66\%). In this conception, the experimentation amounts to a simple observation of the facts that requires from the scientist the use of sharpened senses in order to describe faithfully what he sees, hears, touches and feels. In this perspective, one can understand why, for a large number of these students, the scientists must exclude from their reasoning all recourse to their religious convictions (62\%).

Thus, they are not keen to the fact that in order to observe, a theory is necessary because the experimentation requires the use of a theory that guides it whereas for these students the experimentation precedes (75\%) the theory. Also, the analysis of the principal themes reveals a cohabitation of several contradictory explanatory systems. For example, while adhering to the representations described above which could be classified as "naïve inductivism" according to our conceptual framework, they stated that the development of scientific theories is based only on logico-mathematical reasoning (72\%).

Finally, we noted that for a large number of these students, today's science results from an improvement of the science of the past (61\%).Thus, for these students, the scientific progress results in an improvement of the scientific theories (81\%) and the direction followed by the today's science is determined by orientations taken by the scientists at previous times (72\%).For these students, the science pursues a continuous progress without revolutionary change as qualified by the historian of the sciences Kuhn (1972).

\section{Implications to Science Teacher Education}

- On the didactic plan, the teaching of the history of science will probably place these students in situation of conflict towards their representations identified in this research.

- Such a teaching will also permit to make them see the importance and the utility of proceedings, controversies, conflicts, mistakes and classifications in the development of the scientific knowledge.

- Unfortunately, such a teaching is rarely put in practice in the formation of the teachers of the primary in spite of the ministerial instructions and the research that propose a didactic exploitation of the history of the sciences.

- The science teachers still present science like a finished building where concepts, models and theories are constructed entirely and cannot be submitted to refutation because of their acceptance by the scientific community.

\section{References}

[1] Organization for Economic Co-operation and Development, Declining enrolment in science \& Technology Studies. Is it real? What are the causes? What can be done?, 2005.

[2] Niedderer, H., "Recherche et développement en didactique de la physique à l'université; résultats et tendances (Research and development in didactics of the physics to the University; Results and tendencies)", Didaskalia, 14, 95-113, 1999.

[3] Posner, G. J., Strike, K. A., Hewson, P. W. and Gertzog, W. A., "Accommodation of a scientific conception: Toward a theory of conceptual change", Science Education, 66, 211-227, 1982.

[4] Matthews, M. R., "Science Education and the Scientific Revolution: a way to learn about science", Review of Science, Mathematics and ICT Education, 1(1), 49-61, 2007.

[5] Ministry of the Education of Quebec, Programme des programmes - Domaine de la mathématique, de la science et de la technologie (Program of the programs - Domain of the mathematical, the science and the Technology), 121-161, 2001.

[6] Pomeroy, D., "Implications of teachers' beliefs about the nature of science: Comparison of the beliefs of scientists, secondary science teachers, and elementary teachers", Science Education, 77 (3), 261-278, 1993.

[7] Orlandi, E., "Les conceptions d'enseignants de biologie à propos de la démarche expérimentale" (The conceptions of biology teachers about the experimental gait), in Conceptions et connaissances, Peter Lang, 133-143, 1994.

[8] Osborne, J., Simon, S. and Collins, S., "Attitudes towards science: A review of the literature and its implication", International Journal of Science Education, 25(9), 1049-1079, 2003.

[9] Tsai, C. C., "Nested epistemologies: Science teachers' beliefs of teaching, learning and science", International Journal of Science Education, 24(8), 771-783, 2002.

[10] Trudel, L. and Métioui, A., "Diagnostic of Attitudes towards Science Held by Pre-Service Future Science Teachers", The International Journal of Science in Society, 2(4), 63-84., 2011.

[11] Le Strat, S., Épistémologie des sciences physiques (Epistemology of the physical sciences), Édition Nathan, Paris, 1990.

[12] Shapin, S., The Scientific Revolution. The University of Chicago Press, Chicago, 1996. 
[13] La Recherche, Dossier - Fraudeurs, les chercheurs? (Smugglers, the researchers?), 323, September, 1999.

[14] Métioui, A. and Trudel, L., "Quebec Secondary Physics Teachers and Modern Science: The Case of the Concept of Matter", The international Journal of Science in Society, 3(1), 177-190, 2012.

[15] Bunge, M., Épistémologie (Epistemology), Maloine s.a. éditeur, Paris, 1983.

[16] Kuhn, T. S., The structure of scientific revolutions. Chicago Press., Chicago, 1962

[17] Larousserie, D., "Au-delà d'Einstein, La révolution de l'espacetemps" (Beyond Einstein, The revolution of space-time), Sciences et avenir, 52-59, 2005.
[18] Bachelard, G., La philosophie du Non (The philosophy of the No), Presse universitaires de France, Paris, 1981.

[19] Gribbin, J., Science: a history 1543-2001, Penguin Books, London, 2002.

[20] Popper, K. R., Objective Knowledge. Oxford University Press, Oxford, 1972.

[21] Capra, F., Le temps du changement (The time of the change), Édition du Rocher, Monaco, 1983. 